\title{
PRÁTICA FAMILIAR E ESCOLAR NA ESCOLHA DO TRABALHO DO JOVEM
}

Marcos Antonio Batista da Silva

Centro Universitário FIEO, Osasco, SP, - Faculdade Nossa Cidade ,Carapicuíba SPBrasil

RESUMO: Este estudo é o resultado de uma pesquisa que aprofundou a discussão sobre a categoria juventude e as repercussões da prática familiar e escolar, na escolha do trabalho dos jovens e inserção laboral. O desenvolvimento deste estudo foi norteado pelo referencial teórico sócio-histórico. A pesquisa contou com 50 jovens participantes de ambos os sexos, com idade entre 17 e 20 anos, estudantes do $3^{\circ}$ ano do Ensino Médio, de escola pública, no município de Carapicuíba, SP, em busca do primeiro emprego. Para coletar as informações na escola dos participantes, utilizamos questionários e a técnica de grupo focal, além da nossa vivência com essa temática. A pesquisa teve duração de um ano, e seus resultados atendem às exigências para a obtenção do Mestrado em Psicologia Educacional. Como conclusão, inferimos que os resultados sinalizaram para a necessidade do fortalecimento da autoestima do jovem, para a necessidade de a escola assumir o propósito de prepará-lo para o mundo do trabalho, compreendendo o seu entorno social. Observamos ainda que a família, além de garantir sobrevivência e estabilidade emocional, necessita dar condições para o jovem fazer suas escolhas. Contudo, os jovens, apesar de estarem inseridos em uma sociedade que vive uma crise no mercado de trabalho com desemprego e falta de capacitação, valorizam o trabalho, seja para realização pessoal, fonte de renda, meio de ganhar independência ou como contribuição social. No que tange à inserção no mercado de trabalho, creditam como dificuldades a falta de experiência e capacitação inadequada frente às novas dinâmicas do trabalho.

Palavras- chave: jovem; mundo do trabalho; escola; família.

ABSTRACT: This study is the result of research that deepened the discussion about the youth category and the impact of family practice and school, the choice of youth employment and labor insertion. The development of this study was guided by theoretical socio-historical. The research involved 50 young people of both sexes, aged between 17 and 20 years, students in the 3rd year of high school, public school in the town of Carapicuiba, SP, seeking their first job. To collect the information of participants in school, we used questionnaires and focus groups, as well as our experience with this topic. The search lasted one year, and the results meet the requirements for obtaining a Masters in Educational Psychology. In conclusion, we infer that the results signal the need to strengthen the self esteem of the young, the need to take to school for the purpose of preparing him for the work world, including the social environment. We also observed that the family, and ensure survival and emotional stability, need to empower the young to make their choices. However, young people, despite being embedded in a society that is experiencing a crisis in the labor 
market with unemployment and lack of training, value the work, whether for personal achievement, a source of income, means of gaining independence or as a social contribution. Regarding the insertion in the labor market, credit problems as the lack of experience and inadequate training due to the new dynamics of work.

Keywords: Young; world of work, school, family.

\section{Introdução}

Este estudo é resultado de uma pesquisa sobre as repercussões da prática familiar e escolar na escolha do trabalho do jovem de modo a subsidiar educadores, orientadores profissionais, psicólogos e outros especialistas que atuam na formação e orientação de jovens, especialmente para a escolha profissional e inserção no mundo do trabalho. Toma como principio que a categoria juventude é uma construção social, num contexto de diversidades socioculturais. Dentro desta forma de perceber o jovem, procura situar elementos norteadores para o enfrentamento dos impasses próprios do mundo globalizado, como as novas dinâmicas do trabalho, a educação, a família e a própria juventude.

Discutir a relação entre trabalho e juventude é mais do que analisar a questão da escolha profissional e da obtenção de um emprego. Significa contribuir para a formulação de um projeto de vida, clivado de valores sobre o sentido do trabalho como meio de realização pessoal e de participação na transformação do mundo. Esta atitude inclui reflexões sobre a própria história de vida, com suas metas, desafios e sonhos. O trabalho é também um meio de construção da identidade dos jovens adolescentes. $\mathrm{O}$ melhor caminho para isso é, antes de tudo, dar voz ao sujeito do processo.

$\mathrm{Na}$ sociedade globalizada e de consumo, preparar para escolhas com princípios éticos, na idade das opções, é vital para o desenvolvimento humano. Em cada época da história, educadores, intelectuais e instituições têm-se preocupado com o processo e socialização e de profissionalização do jovem adolescente que, largado à deriva, poderia descambar para as práticas de violência. Dados divulgados pelo Ministério da Justiça sobre O mapa da violência : os jovens do Brasil(2011) a partir de um levantamento feito pelo Instituto Sangari, nos revelam que a taxa de homicídios entre os jovens de 15 a 24 anos cresceu de 30 para 52,9 por 100 mil habitantes entre 1980 e 2008. 
Não é sem motivo que Instituições e Organismos como a UNESCO (Organização das Nações Unidas para a Educação, a Ciência e a Cultura), OIT (Organização Internacional do Trabalho),tomam como foco a necessidade da formulação de políticas que contemplem a questão da formação para o trabalho e da inserção profissional do adolescente. Acreditamos que a compreensão da juventude está circunscrita, de maneira integrada, nas relações sociais, culturais, políticas e econômicas, assim como no processo de formação da identidade.

\section{Adolescência e Juventude: diferentes olhares}

Trabalhar com temas envolvendo a juventude ${ }^{1}$ geralmente exige do pesquisador alguns recortes, objetivando uma definição mais precisa sobre esta categoria, tal é a multiplicidade de abordagens que contém este conceito. Diferentes concepções no que se refere ao próprio “objeto” hora em estudo, o jovem e a análise da diversidade sociocultural que os envolvem. Há fortes razões para estudar o atual contingente jovem brasileiro, destacadamente em primeiro lugar: magnitude - Em 2007, segundo a Pesquisa Nacional por Amostra de Domicílios do Instituto Brasileiro de Geografia e Estatística (Pnad/IBGE), o Brasil possuía cerca de 50,2 milhões de jovens entre 15 e 29 anos, o que correspondia a 26,4\% da população.

Em segundo lugar, pela necessidade de se fazer uma reflexão sobre a educação de jovens. Neste sentido, quanto mais se articula o conhecimento frente ao mundo, mais os educandos se sentirão desafiados a buscar respostas, e conseqüentemente quanto mais incitados, mais serão levados a um estado de consciência crítica e transformadora frente à realidade. Esta relação dialética é cada vez mais incorporada na medida em que, educadores e educandos se fazem sujeitos do seu processo.

Em terceiro lugar, por estudar a juventude e alguns fatores que acontecem neste período. O tema juventude tem sido bastante discutido na sociedade contemporânea nos ultimo anos, ampliando sua visibilidade a exemplo do discurso inaugural da posse da

\footnotetext{
${ }^{1}$ A definição de juventude pode ser desenvolvida por uma série de pontos de partida: como uma faixa etária, um período da vida, um contingente populacional, uma categoria social, uma geração... Mas todas essas definições se vinculam, de algum modo, à dimensão de fase do ciclo vital entre a infância e a maturidade. (Abramo e Leon, 2005, p.6)
} 
atual Presidenta do Brasil Dilma Rousseff, que abordou a questão social da juventude e suas implicações para um desenvolvimento de orientação democrática e popular.

Contudo é preciso explorar este temática iniciando por dizer que existe hoje, no Brasil, um uso concomitante de dois termos, adolescência e juventude, que ora se superpõem, ora constituem campos distintos, mas complementares, ora traduzem uma disputa por distintas abordagens. Contudo, "as diferenças e as conexões entre os dois termos não são claras, e, muitas vezes, as disputas existentes restam escondidas na imprecisão dos termos.” (Abramo e Leon, 2005, p.6).

O termo adolescência ${ }^{2}$ tem como fundo um período da vida, marcado pela puberdade, pelas oscilações emocionais e características comportamentais. Esta é uma perspectiva mais utilizada pelas ciências jurídicas e da saúde. O ordenamento jurídico que emergiu da Constituição de 1988 propiciou um amplo debate na sociedade brasileira acerca dos direitos da infância e da adolescência. Este debate incluiu os aspectos pedagógicos e sociais da temática da adolescência, e definiu como faixa etária dessa fase da vida o período que vai dos 12 aos 18 anos de idade, conforme estabelece o (ECA) Estatuto da Criança e do Adolescente, em consonância com algumas teorias sociológicas e psicológicas, que foram utilizadas para explicar os problemas sociais da adolescência. "Art. $1^{\circ}$ Esta Lei dispõe sobre a proteção integral à criança e ao adolescente." (ECA)

proteção que na sua condição de menor requer, por parte da família, da sociedade e do Estado”.. Diante das influências normativas do cenário mundial o Brasil passou a adotar suas principais orientações. Entretanto a necessidade de normatizar e naturalizar os

\footnotetext{
${ }^{2}$ A noção de adolescência está mais consolidada, clara e difundida na sociedade brasileira, contando com maior institucionalidade (da qual o marco legal, o ECA, e a existência de conselhos tutelares e de defesa em todos os níveis da federação são sua maior expressão), maior número de ações e atores comprometidos a sustentarem sua postulação. Para registro de tal noção, recolhemos a definição constante do Relatório da Situação da Adolescência Brasileira, elaborado e publicado pela UNICEF em 2002: logo no início do texto, toma-se como ponto de partida a noção de adolescência como uma "fase específica do desenvolvimento humano caracterizada por mudanças e transformações múltiplas e fundamentais para que o ser humano possa atingir a maturidade e se inserir na sociedade no papel de adulto"; acrescenta-se, logo em seguida, que é "muito mais que uma etapa de transição, contemplando uma população que apresenta especificidades, das quais decorrem uma riqueza e potencial únicos”. .(Abramo e Leon, 2005, p.29)
} 
conceitos ocorre simultaneamente aos momentos críticos de consolidação de novas etapas do sistema capitalista.

Em quarto lugar, pela necessidade de refletir sobre a posição política e econômica nas questões do emprego para jovens. Na sociedade contemporânea o trabalho é essencial para o desenvolvimento do sujeito e sua interação com a sociedade. O período de hegemonia do projeto neoliberal em nosso país provocou profunda desestruturação do mercado de trabalho e a diminuição do papel do Estado no provimento de políticas sociais. O resultado da política econômica desse período foi o baixo crescimento econômico e o achatamento da renda das famílias. A conjunção desses fatores impôs aos filhos e filhas em idade escolar a necessidade de buscar formas de incremento da renda familiar.

Atualmente, este temática da juventude e inserção laboral se reapresenta na agenda das principais universidades e centros de pesquisa do Brasil, procurando responder aos questionamentos e desafios que emergem de um mundo em transformação. Vários pesquisadores têm-se debruçado sobre esta temática, a exemplo de (Sposito, 2009; Abramo \& Leon, 2005a; Dayrell, 2003; Corrochano \&, Nakano, 2009; Peregrino, 2009). Talvez tenha sido Marx quem primeiro definiu a condição do jovem pela perspectiva sócio-histórica. Nesta, o jovem se define nas relações sociais. Assim, por exemplo, tal como um negro é um negro, e só se torna escravo num determinado contexto, podemos dizer que existem tantos modelos de juventude quantos a cultura permitir. Quem trabalha com jovens pode perceber que ser jovem é ser um pouco polivalente, é estar conectado com varias coisas simultaneamente, sem estar, aparentemente, ligado a coisa alguma.

O jovem costuma se angustiar profundamente com as relações afetivas, com os vínculos dos relacionamentos grupais. Não existe uma maneira única de ser jovem. Cada um constrói, a sua maneira, um modo de ser, de agir, de confabular e de fazer sua história, dentro de uma circunstância dada. O sentido existencial do jovem está em formação, o que o faz necessitar de coisas concretas e de sonhos. É próprio ao jovem ansiar por oportunidades, formular projetos de vida, deixar-se fascinar pela liberdade, sonhar com experiências de realização no trabalho, nas amizades, na sociedade. Se, de um lado, o jovem tem expectativas, de outro, as instituições, o mercado, a família e a 
sociedade também têm seus projetos. A dificuldade do jovem é integrar essas dimensões, uma vez que sua subjetividade se constrói e é construída no conjunto das relações sociais e de acordo com seu modo de assimilar e de responder às solicitações objetivas do cotidiano e da história.

Em grande parte das escolas há uma preparação para a iniciação jovem no ensino superior, em detrimento para a inserção no mundo do trabalho. Em nossa cultura, o vestibular ainda é visto como um marco principal de passagem da juventude para a vida adulta. Constantemente o vestibular é realizado de forma alienada, principalmente devido ao fato do jovem, mesmo depois de ter passado por ele, permanecer em simbiose com a família, continuando dependente, sendo sustentado ainda por alguns anos. Porém a grande maioria dos jovens tem por motivos socioeconômicos, abreviado os estudos para ingressarem no mundo do trabalho sem uma formação eficiente e eficaz.

Olhando para o universo jovem de nosso país observamos que essa juventude não é apenas uma massa, mas é uma juventude que traz seus sonhos, esperanças, suas angústias, seu jeito próprio. É preciso que sejam abandonadas as práticas paternalistas ou assistencialistas que geram dependência e tutela, para que possamos contribuir para a formação de indivíduos autônomos e emancipados socialmente e economicamente, fomentando ações de capacitação profissional, estimulando-os para que retornem a uma vida de estudos e que sejam atuantes em suas comunidades.

Contudo é necessário que sejam criadas condições concretas de melhorias do processo de escolarização, objetivando a valorização dos hábitos de leitura, do pensamento lógico, do ensino de habilidades profissionais, além de apoiá-los na busca por empreendimentos geradores de renda, estimulando a criatividade e o comportamento empreendedor, sensibilizando-os para os ideais do associativismo como estratégia indutora de desenvolvimento social em nossa sociedade. Para Freire (1983), uma nova educação só poderia ser possível com uma profunda mudança da sociedade, da política, da ética, do cotidiano dos indivíduos e dos grupos sociais.

Sabemos que o Brasil enquanto país em desenvolvimento tem capacidade de mobilizar recursos financeiros e institucionais adequados para o enfrentamento da problemática da juventude no contexto educacional e no mundo do trabalho. Sempre 
serão louvadas iniciativas de indivíduos, associações e empresas particulares como também medidas governamentais de políticas públicas que vem na direção de atender as demandas da juventude brasileira. Discutir a relação entre trabalho e o jovem é mais do que analisar a questão da escolha profissional e da obtenção de um emprego. Significa contribuir para a formulação de um projeto de vida, clivado de valores sobre o sentido do trabalho como meio de realização pessoal e de participação na transformação do mundo.

\section{Juventude, trabalho e oportunidades}

$\mathrm{Na}$ sociedade globalizada e de consumo, preparar para escolhas com princípios éticos, na idade das opções, é vital para o desenvolvimento humano. Em cada época da história, educadores, intelectuais e instituições têm-se preocupado com o processo e socialização e de profissionalização do jovem que, largado à deriva, poderia descambar para as práticas de violência. A desigualdade social e as contínuas transformações no mercado de trabalho repercutem na vida e na formação do jovem. Essa realidade provoca o poder público, a sociedade e a família a discutirem a realidade do emprego, da capacitação profissional e da necessidade de políticas públicas voltadas à população juvenil. Tal procedimento compreende não apenas a formulação e a implementação de políticas de inserção, como também de programas socioculturais, capacitação profissional e para a cidadania, a oferta de oportunidades de experiências de vida e o próprio conceito de trabalho.

Podemos definir trabalho como toda atividade pela qual o ser humano utiliza sua energia física e psíquica para satisfazer suas necessidades ou para atingir um determinado fim. É por intermédio do trabalho que o ser humano transforma a natureza, constrói e reconstrói cultura e dá sentido à vida. É pelo trabalho que o homem pode moldar e mudar a natureza e, ao mesmo tempo, alterar a si próprio. O mundo do trabalho inclui uma abrangente diversidade de capacidades heterogêneas, que vai do senso estético ao fazer.

O trabalho permite aos sujeitos expandir suas energias, desenvolver sua criatividade e realizar suas potencialidades. A ação de trabalhar não é apenas extrair 
materiais da natureza, mas sim alterar seu estado natural, definir e melhorar sua utilidade. Este ato é carregado de aspectos sociais, em vista da manutenção material e imaterial pessoal e da comunidade, bem como da coesão social (Braverman, 1987). Segundo os clássicos da sociologia e da psicologia, cada descoberta na linha da tecnologia e da ciência produz também uma mudança na divisão social do trabalho.

O papel do indivíduo no mundo do trabalho contribui para a formação de sua identidade. Tão ligado está o trabalho à definição de nossa identidade que, quando somos apresentados a uma pessoa, a pergunta mais imediata que fazemos, não é de onde ela vem, ou quem é sua família, mas o que ela faz e em que trabalha. Se o trabalho assume tal importância em nossa vida, é natural que não nos contentemos com o que ele nos traz. A metamorfose do capital, descrita por Marx (1985), deixa perceber que o trabalho é a ação de transformar o mundo e a nós mesmos. Em si, o trabalho é bom, mas pode ser um mal em determinadas circunstâncias.

Prisioneiro de mecanismos de exploração e alienação, o trabalho deixa de ser meio de realização e se transforma em instrumento de coisificação que aborta muitas perspectivas de criatividade e de um sentido emancipador da vida. No mundo do lucro e da produção em massa, a desigualdade social enfraquece as possibilidades de realização das potencialidades humanas, particularmente dos mais jovens. O capitalismo, em países como o Brasil, traz uma cultura de exploração que produz e reproduz a desigualdade social, impregnada nas políticas econômicas e públicas.

Nossa sociedade é marcada pela contradição. Se o trabalho é fonte de exploração, por outro lado, é também fonte de emancipação. Por isso nos perguntamos se é possível ao adolescente extrair do processo de trabalho a felicidade, e nele manifestar suas potencialidades e criatividade? Entendemos que a educação e a cultura tendem a ajudar o jovem a encontrar um sentido para o trabalho, que contribua para a construção de um sentido para sua vida. (Antunes, 2001, p.22)

Uma vida cheia de sentido fora do trabalho supõe uma vida dotada de sentido dentro do trabalho. Não é possível compatibilizar trabalho assalariado, feitichizado/alienado com tempo (verdadeiramente) livre. Uma vida desprovida de sentido no trabalho é incompatível com uma vida cheia de sentido fora do trabalho. Em alguma medida, a esfera 
fora do trabalho estará maculada pela desefetivação que se dá no interior da vida laboral. (Antunes, 2001, p.22)

Um princípio norteador para compreendermos a importância do sentido do trabalho para o adolescente é que o homem modifica o mundo e a si mesmo, produz cultura e se autoproduz, ou seja, é produto e produtor da cultura. Na contemporaneidade, a produção não se dá apenas no campo material, mas também o imaterial. A equivalência física e simbólica dos produtos leva tudo a se transformar em mercadoria. Mesmo as relações entre as pessoas ganham contornos mercadológicos (Souza Neto, 2008), fundados numa filosofia do consumismo, pela qual o processo produtivo se torna objetivo do homem, em vez de o homem ser o objetivo da produção.

Neste quadro de reflexão, cabe evidenciar a relação que se estabelece entre adolescente e trabalho, vital na experiência do primeiro emprego. É uma espécie de passaporte para a consolidação da autonomia, da formação da identidade, do reconhecimento como alguém pelo grupo e pela família, é poder escolher e adquirir coisas. Para o jovem, o ingresso no mundo do trabalho constitui-se, tradicionalmente, em um marco da passagem da condição juvenil para a vida adulta.

A inserção no mundo do trabalho tem sido uma das preocupações da juventude e também, dos educadores e gestores das políticas públicas. Existe uma convicção generalizada de que é necessário desenvolver programas e ações que melhorem a situação atual, levando-se em conta o aumento da vulnerabilidade social e pessoal deste segmento social, além da limitada oferta de oportunidades e da falta de preparo específico do jovem para assumir funções de trabalho.

Mesmo aqueles que conseguem superar todas as dificuldades e terminar uma faculdade, não têm garantia de empregos. As diferenças entre a teoria da escola nos cursos de forma geral e a prática no mercado de trabalho acabam deixando a escolaridade com um papel modesto frente ao treinamento em serviço, ou estágio na preparação do jovem trabalhador. O diagnóstico dominante aponta para as dificuldades de aproveitar oportunidades, especialmente em obter o primeiro emprego, em função do despreparo e da desqualificação frente à competitividade. Essa realidade coloca em xeque a proposta pedagógica da política educacional e da forma de pensar e de agir das 
famílias. A realidade de jovens brasileiros aponta como alternativa uma reformulação das políticas públicas de primeiro emprego, não apenas no sentido de estimular a busca precoce do mercado de trabalho, mas também de construir um projeto de vida, preparar para a convivência humana, para aprender a ser, saber e fazer. Portanto, a adquirir uma identidade pautada na ética do cuidar de si, do outro e do planeta. Ingressar no mercado de trabalho, sem base escolar, pode ser um fator desfavorável ao desenvolvimento de uma trajetória profissional satisfatória.

Numa sociedade marcada pela transitoriedade, repleta de sinais confusos, propensa a mudar com rapidez e de forma imprevisível, a escola, a família e as demais instituições devem cuidar da formação ético-social e profissional, para que o jovem possa modificar sua biografia e a de seus companheiros. A procura por jovens com experiência profissional é um fator que eleva a importância do treinamento em serviço, para obter e aperfeiçoar as habilidades e conhecimentos profissionais. Com isso, uma grande parcela da melhoria do sistema de ensino no país cabe às empresas. No cenário atual, caracterizado pela tecnologia e pela mudança de valores, várias são as instâncias que respondem pela formação do adolescente.

Para os jovens, a escolha de uma profissão passa por uma questão de identidade, de encontro de seu espaço social, de descoberta e construção de um projeto de vida e, sobretudo, de oportunidades. Neste sentido, o jovem necessita de grupos de apoio para subsidiar o auto desenvolvimento. Entre esses grupos destacam-se a família, a escola e a comunidade.

\section{Método}

Realizamos uma pesquisa, de caráter qualitativo que procurou valorizar a fala do jovem, por meio de um questionário, com cinquenta jovens de ambos os sexos, com idade entre 17 e 20 anos $^{3}$, de camadas populares, matriculados no terceiro ano do ensino

\footnotetext{
3 Ainda que para fins de definição de política pública, legislação e pesquisa seja possível fixar um recorte etário para determinar quem são os jovens, deve-se ter em conta que "juventude” é uma categoria em permanente construção social e histórica, isto é, varia no tempo, de uma cultura para outra, e até mesmo no interior de uma mesma sociedade. No Brasil, a adoção do recorte etário de 15 a 29 anos no âmbito das políticas públicas é bastante recente. A praxe anterior tomava por "jovem” a população na faixa etária entre 15 e 24 anos. A ampliação desta faixa para os 29 anos não é uma singularidade brasileira, configurando-se, na verdade, numa tendência geral dos países que buscam instituir políticas públicas de juventude. Duas são as principais justificativas da mudança: maior expectativa de vida para a população em geral, e maior dificuldade desta geração em ganhar autonomia em função das transformações no mundo do trabalho. (Andrade, 2008, p.26).
} 
médio de uma escola pública de município de Carapicuíba, na Grande São Paulo, Brasil.

A pesquisa foi realizada na própria escola dos sujeitos, numa sala de aula, coletivamente, após breve explicação dos objetivos do trabalho pelo aplicador da pesquisa e da devida autorização dos pais os responsáveis dos participantes menores de idade. Não foi obrigatório o preenchimento do material impresso, dando-se ao participante a liberdade de devolvê-lo em branco. Foi utilizado um questionário com perguntas abertas e fechadas, de autopreenchimento e sem identificação pessoal de aluno. O questionário foi dividido da seguinte maneira. Em primeiro lugar foi levantado o perfil do participante através de perguntas que nos informariam sobre: sexo, idade, raça, religião, naturalidade, estado civil entre outros.

Em segundo lugar, foi levantado informações sobre a família e domicílio número de pessoas, grau de parentesco, irmãos, renda familiar, dados socioeconômicos. Em terceiro lugar levantamos dados sobre cultura e lazer - literatura, atividades, tecnologia, tempo livre, atitudes e comportamento. E por fim foi solicitado questões de reflexões sobre algumas temáticas: o mundo do trabalho, legislação trabalhista, profissões, escola, expectativa profissional, trabalho, projeto de vida e família.

Dos cinquenta entrevistados, escolhemos nove para participar de um grupo focal de reflexão sobre temas relacionados à inserção no mundo do trabalho, à escola, à família e às das escolhas profissionais. A dinâmica do grupo focal permite uma forma rápida, fácil e prática de pôr-se em contato com a população que se deseja investigar, e, ao mesmo tempo, de aprofundar alguns temas nem sempre abordados num primeiro momento. Não obstante haver críticas a essa metodologia, ela foi importante para o diálogo do pesquisador com os adolescentes e destes entre si, no sentido de desvelar um pouco mais o fenômeno estudado.

\section{Resultado e discussão}

De certa forma, o jovem contemporâneo vive um paradoxo: por um lado, há uma padronização excessiva de gostos e de atitudes e, por outro lado, a condição de jovem que o define como alguém que possui uma grande inquietude, buscando um 
sentido para a sua vida. Mas nem sempre os contextos nos quais esse jovem se insere contribuem para o desenvolvimento do pensamento dialético, questionador, transformador. Portanto seja no âmbito familiar, escolar ou no trabalho acreditamos que estas possibilidades se não estiverem acopladas a uma rede de sustentação mais ampla, a exemplos de políticas públicas para a juventude, onde estes espaços possam garantir o desenvolvimento de um sentido para a juventude, sem os quais, o jovem terá dificuldades em exercitar o seu papel de ator social.

Os jovens estão em todos os lugares e a todo tempo, eles querem ser notados, capacitados, educados e inseridos nos espaços que lhes cabe, mas para isto necessitam de serem preparados para fazerem escolhas positivas, que sejam capacitados em termos éticos, cuidando de si e do outro, se escolarizando e que estejam aptos a uma inserção no mercado de trabalho, visando crescimento e desenvolvimento sociais. Falar sobre a temática da juventude e trabalho “ exige do pesquisador alguns recortes, a fim de objetivar uma definição mais precisa sobre o adolescente pesquisado, tendo em vista a diversidade sociocultural que o envolve." (Batista da Silva e Munhoz, 2010, p.235).

Para efeitos deste estudo da percepção de um jovem adolescente participante da pesquisa quando lhe foi perguntado o que é ser jovem e qual sua percepção sobre o trabalho, acreditamos ser importante: Em primeiro lugar, considerar que os jovens apesar de estarem inseridos em uma sociedade onde eles têm vivido uma crise no mercado de trabalho como desemprego e falta de capacitação adequada, valoriza o trabalho, seja para realização pessoal, como fonte de renda, como meio de liberdade, com contribuição social. Entretanto para tal é necessário que o jovem tenha um trabalho e que segundo eles é difícil a inserção devido à falta de experiência e capacitação adequada frente às novas dinâmicas do trabalho no mundo globalizado, e em constante transformação devido ao impacto que causam as novas tecnologias e flexibilidade e individualização do trabalho.

Em segundo lugar, inserir o jovem no mundo do trabalho supõe políticas públicas de inserção laboral, onde sejam priorizadas jornadas de trabalho compatíveis com os estudos, programas de capacitações. Pensar nesta questão é entender que estas ações não são apenas privilégios para os jovens, mas sim, ações que geram conseqüências em toda comunidade entre eles a escola, beneficiando a família, 
melhorando a qualidade de vida nas cidades, diminuindo a violência e construindo projetos de vida. O que o jovem percebe sobre si mesmo e como percebe o trabalho, são dados importantes para a compreensão de novos desafios decorrentes da globalização, das novas tecnologias e educação e dos níveis de qualificação para o ingresso no mundo do trabalho.

Em por fim, perceber que os indicadores que evidenciam o relato dos jovens adolescentes pressupõem percepções que o jovem não é um ser isolado sendo formado pelo processo em curso tendo vivências e experiências passadas e um futuro potencial. O que pressupõe que as pessoas pensam, sentem, agem, e têm reações por desejos e aspirações suscitando assim valoração, desencadeando uma percepção e valoração no contexto do seu próprio processo histórico social dimensionado ações reflexivas.

\section{Considerações finais}

O percurso de socialização dos jovens adolescentes participantes da pesquisa passa pelas famílias de camadas populares que são pertencentes. Isto implica que vivenciaram este processo com uma população dos centros urbanos, cujas condições de habitação muitas vezes são precárias, assim como o acesso a saúde, educação, saneamento básico e renda familiar reduzida. Nestas famílias os cuidados com os filhos em seu processo de socialização primário cabem principalmente a figura materna.

Onde a família é citada em diferentes aspectos a exemplo de modelo de conduta no desempenho de seus papéis sociais e das normas e valores. O que implica que a família pode tanto ajudar quanto dificultar o jovem no momento de suas escolhas e entre elas a profissional, no momento em que este jovem está construindo sua identidade tanto pessoal como vocacional. O trajeto escolar que estes jovens adolescentes percorrem, nem sempre é um caminho de possibilidades para que se solidifiquem ações que promovam a capacitação e potencialidade para que eles consigam uma inserção laboral. Ações estas que deveriam ser direcionadas ao fortalecimento das habilidades, da empregabilidade, propiciando um futuro próximo com tomada de decisões favoráveis. Deste modo cabe ao sistema educacional um papel mais representativo na percepção de comportamentos, buscando significados nas diversidades socioculturais que contribuam para reflexão e propiciem uma melhor 
qualidade nesta fase. Como perceber o seu entorno social e desenvolver um trabalho educativo, expressando o desenvolvimento de competências pessoais e sociais que alavancam o jovem na busca uma inserção social em sentido abrangente incluindo o trabalho para que ele possa fazer parte de uma sociedade globalizada, com impactos tecnológicos, que necessitam aproximar a prática ao discurso no processo de socialização da juventude.

Deste modo contribuindo para uma grande parcela da população jovem como os participantes desta pesquisa que têm os caminhos para o mundo do trabalho de modos íngremes. Um dos motivos principais dos relatos dos jovens participantes desta pesquisa no que se refere à dificuldade de inserção no mercado de trabalho é a falta de experiência, uma característica forte que é atribuída a este grupo. Com base nessas considerações, a transição escola-trabalho do jovem participante da nossa pesquisa para vivenciar este novo ambiente que ele quer se inserir - mundo do trabalhoprincipalmente numa sociedade, propensa a mudar com bastante rapidez, passa pela família, a escola, e as demais instituições que precisam cuidar da formação ética, social e profissional, para que o jovem possa modificar sua biografia e a de seu grupo.

Diante destas considerações, acreditamos que a escola precisa abrir um espaço para o jovem discutir projeto de vida e não se fala em projeto de vida sem discutir o trabalho, onde podem ser abordadas sobre o tema as inquietações dos jovens, temores, expectativas, possibilitando-lhe a perceber o trabalho como realização pessoal e meio de participação, cooperação e sobrevivência. Originando-se assim uma escola que compartilhe o seu papel transformador entorno social do jovem na sociedade contemporânea. Contudo um trabalho para a juventude supõe políticas públicas de inserção ao mundo do trabalho, onde sejam priorizadas jornadas de trabalho compatíveis com os estudos, programas de capacitações.

Pensar nesta questão é entender que estas ações não são apenas privilégios para os jovens, mas sim, ações que geram conseqüências em toda comunidade entre eles a escola, beneficiando a família, melhorando a qualidade de vida nas cidades, diminuindo a violência e construindo projetos de vida. 


\section{Referencias bibliográficas}

ABRAMO, H, W. , LÉON, D. O. (2005). Juventude e adolescência: referências conceituais. São Paulo: Ação Educativa.

ANDRADE, C.C. Juventude e trabalho: alguns aspectos do cenário brasileiro contemporâneo. Mercado de Trabalho, SP: IPEA, n38, Nov.2008

ANTUNES, R. (2001). Os sentidos do trabalho. Ensaio sobre a afirmação e a negação do trabalho. São Paulo: Boitempo Editorial.

BATISTA DA SILVA, Marcos. A.; MUNHOZ, M. L. P.(2010). Percepção do adolescente sobre a influência da família na escolha profissional. In: XVII Jornadas de Pesquisa e Sexto Encontro de Pesquisadores em Psicologia do MERCOSUL. Ciudad de Buenos Aires, Repúbl : Ediciones de la Facultad de Psicología - Universidad de Buenos Aires, v. 1. p. 235-237.

BRASIL.(1995). Estatuto da criança e do adolescente. $5^{\text {a }}$ ed. São Paulo: Saraiva.

BRAVERMAN, Harry. (1987). Trabalho e capital monopolista. Rio de Janeiro: LTC.

CORROCHANO, M.C; NAKANO, M (2009). Jovens e Trabalho: In SPOSITO, M.P. (Org.) Estado da Arte sobre juventude na pós-graduação brasileira: educação, ciências sociais, serviço social (1996-2006), vol.2. Belo Horizonte: Argvmentvm.

DAYRELL, Juarez, (2003) O jovem como sujeito social. Revista Brasileira de Educação, no. 24, p.40-51, set/out/nov/dez.

FREIRE, P. (1983) Pedagogia do oprimido. 12ª edição. Rio de Janeiro: Paz e Terra.

IBASE \& POLIS. (2005). Juventude Brasileira e Democracia: participação, esferas e política públicas. Relatório Final. Disponível em: http://www.ibase.br/pubibase/media/ibase_relatorio_juventude.pdf.Acesso em :15 jan.2011,

IBGE (2009). Pesquisa Nacional por Amostragem de Domicílios. Acessado em: 15 jan.2011,http://www.ibge.gov.br/home/estatistica/populacao/trabalhoerendimento/pnad 2009/default.shtm.

MARX, K. (1968). Trabalho, juventude e educação politécnica. In BRITO S. (Org.), Sociologia da juventude I: da Europa de Marx à América Latina de hoje (pp. 15-18). Rio de Janeiro: Zahar.

OIT (2009) Trabalho decente e juventude no Brasil. [Brasília]: Organização Internacional do Trabalho, 2009. 220 p.

(1985) . O capital: crítica da economia política. São Paulo: Nova Cultural. 
PEREGRINO, M. "Os estudos sobre jovens na intersecção da escola com o mundo do trabalho", in: SPOSITO M.P (org.), Estado da Arte sobre Juventude na pós-graduação brasileira: Educação, Ciências Sociais e Serviço Social (1999-2006), vol.2. Belo Horizonte-MG: Argvmentvm, 2009.

SOUZA NETO, J.C.; LIBERAL M.M. C (2004). Metamorfose do trabalho da era da globalização. São Paulo: Expressão \& Arte.

(2008). Infância: violência, instituições e políticas públicas. Vol. I, II. São Paulo: Expressão \& Arte.

SPOSITO, M. P(2009). Estudo da Arte sobre juventude na pós-graduação brasileira: Educação, Ciências Sociais e Serviço Social (1999-2006), vol.2. Belo Horizonte: Argvmentvm.

SPÓSITO, Marília Pontes. (1996). Juventude, crise, identidade e escola. In: DAYRELL, Juarez (Org.). Múltiplos olhares sobre educação e cultura. Belo Horizonte: UFMG, 1996

(2007). Espaços públicos e tempos juvenis. São Paulo: Global.

UNESCO. “Políticas públicas de/para/com juventudes”. Brasília: UNESCO, 2004.

UNICEF (2002): Situação da Adolescência Brasileira, UNICEF

WAISELFISZ, Julio Jacobo(2011).Mapa da Violência.Os Jovens do Brasil. Instituto Sangari Ministério da Justiça Brasília- Brasília-DF 